\title{
Trabajo y escritura en Boca de lobo de Chejfec y La mendiga de Aira
}

\author{
JUAN JOSÉ GUERRA Universidad Nacional del Sur - CONICET, Argentina \\ ORCID 0000-0003-0492-9637 \\ jjguerra89@gmail.com
}

\section{Resumen}

Este trabajo analiza las representaciones del trabajo industrial en Boca de lobo de Sergio Chejfec y La mendiga de César Aira. Pero además, las dos novelas exhiben sus respectivos procesos de construcción del relato a través de ciertas escenas de escritura. Estas no solo ponen el acento sobre la dimensión de la escritura como trabajo sino que reenvían a la poética de cada autor. Si, por un lado, la circularidad, la iteración y el carácter conjetural de la trabajada frase son en Chejfec la expresión formal del vínculo entre escritura y melancolía, por otro, el descuido estilístico, la precipitación y los trazos gruesos de la ficción airiana son las señas de una estética de lo malogrado que se presenta al modo de un no-trabajo.

Palabras clave: Aira / Chejfec / trabajo / escritura / literatura argentina

\begin{abstract}
Work and writing in Chejfec's Boca de lobo and Aira's La mendiga

Abstract

This work analyzes the representations of industrial work in Boca de lobo by Sergio Chejfec and La mendiga by César Aira. But in addition, the two novels exhibit their respective story-building processes through certain writing scenes. These not only emphasize the dimension of writing as work but also refer to the poetics of each author. If, on the one hand, the circularity, the iteration and the conjectural character of the elaborate phrase are in Chejfec the formal expression of the link between writing and melancholy, on the other, the stylistic carelessness, the rush and the thick lines of Airian fiction are the signs of an aesthetics of bad writing that is presented as a non-work.
\end{abstract}

Key words: Aira / Chejfec / work / writing / Argentine literature

Recibido: 5/6/2020. Aceptado: 16/7/2020

Para citar este artículo: Guerra, J.J. (2020). Trabajo y escritura en Boca de lobo de Chejfec y La mendiga de Aira. El taco en la brea, 12 (junio-noviembre). Santa Fe, Argentina: UNL. eooo6 DOI: 10.14409/ tb.v1i12.9683 
Publicadas con muy poca diferencia de tiempo, La mendiga (1998) de César Aira y Boca de lobo (2000) de Sergio Chejfec son novelas en las que el mundo del trabajo industrial —aquello que todavía puede ser llamado trabajo industrial, aunque no sea más que una versión desleída de lo que el término designó en el pasado social de Argentina y de la literatura argentina- se encuentra en el centro del dispositivo ficcional. Todavía más: las dos novelas, si bien con énfasis marcadamente distintos, destinan un lugar relevante al edificio emblemático de la modernidad industrial, la fábrica. Por supuesto que, tratándose de estéticas diferentes, los modos de representar ese mundo adoptan formas que se pueden distinguir con nitidez. Porque al tiempo que indagan las condiciones del trabajo en una ciudad periférica de fin de siglo, las dos novelas presentan, cada una, todo un programa de escritura que, desde luego, reenvía a la poética de los autores en general, pero que en este caso particular se resuelve en una exhibición de las instancias de producción de los relatos. En línea con la categoría de "ficciones del trabajo» formulada por Alejandra Laera, se trataría en este caso de dos novelas «en las cuales poner en escena el mundo del trabajo sirve para definir la escritura literaria, la ficción y la relación entre ficción y realidad» (2016:165). En última instancia, las escenas de escritura ponen al descubierto morales de la literatura que permiten establecer una línea de división entre dos poéticas que, aun cuando dirijan su mirada a fenómenos sociales semejantes, producen dispositivos si no antitéticos al menos divergentes que, al tiempo que se inscriben en tradiciones previas lo suficientemente explícitas, abren dos caminos posibles para la literatura que les sigue.

Como dice Beatriz Sarlo, en Boca de lobo «la fábrica es el corazón del mundo» (399). La anatomía geográfica de la ciudad se organiza alrededor de la fábrica, de acuerdo con el fenómeno histórico de formación de suburbios industriales. ${ }^{2}$ El edificio pertenece al orden de lo contundente y lo verdadero; en palabras del narrador: «Quiero decir que de la fábrica emanaba el poder, la contundencia, algo fuerte y amargo a la vez» (11). Lo que insiste en la novela es el elogio del mundo fabril y de su protagonista, el obrero, y ese elogio está desplegado sin atisbos de ironía, ya que, como señala Laera, hay en Boca de lobo «una suerte de auratización del mundo fabril» (2012:205). Desde el punto de vista del narrador, la comunidad proletaria no puede constituirse si no es ante todo como el objeto de un espectáculo. La novela exhibe los movimientos, hábitos y actividades de los obreros por medio de escenas en las que el narrador se dedica a observarlos desde el otro lado de la verja. El elemento que aumenta la extrañeza de esta situación es que él no es el único que realiza esa acción, sino que la esquina o el recodo que sirve como sitio desde donde mirar se puebla de gente también absorta en la contemplación de los obreros, principalmente cuando se encuentran en el momento de descanso. La novela define a los proletarios como una tribu, una masa o un rebaño, un organismo colectivo, «un ser compuesto por numerosos individuos equivalentes y que tiene una vida molecular» (31), que realiza ceremonias y ritos ininteligibles para los observadores - de nuevo, no hacen más que aprovechar el tiempo de descanso antes de reiniciar sus trabajos- que ven una coreografía o una estética ahí donde hay cuerpos en reposo. En efecto, la auratización del mundo fabril solo puede acontecer como resultado de la distancia que media entre el objeto de la mirada y el sujeto que lo percibe. El narrador anónimo no ingresa a la fábrica - no tendría motivos para hacerlo, porque su actividad es otra, pero tampoco se lo propone-, sino que sabe de ella estrictamente lo que escucha de parte de Delia. Las informaciones vacilantes que la joven obrera le comunica componen, por lo tanto, el único relato acerca de la vida dentro de la fábrica. ${ }^{3}$ 
Existen al menos dos modos de organización obrera en el marco de una ostensible situación de deterioro de la condición de los trabajadores, de acuerdo con una serie de indicios que desestabilizan la glorificación de ese mundo operada por el narrador. Por un lado, se describe el sistema de préstamos desinteresados de ropa u otros artículos de primera necesidad, por ejemplo, la pollera de Delia. Y, por otro, se alude a las colectas de dinero que tienen por finalidad ayudar financieramente a algún trabajador en aprietos. Esto se explica por un sistema inverso de préstamos usurarios desarrollado por antiguos obreros que han mejorado su posición social y que ahora emplean su conocimiento del mundo proletario para conseguir un rédito económico. Se trata de préstamos irrisorios, ya que el monto prestado es ínfimo, pero que están sujetos a un interés excesivo. Son utilizados por los obreros para cubrir gastos de subsistencia, como comprar jabón, alimento o pagar un boleto de colectivo. Quiere decir que las condiciones de vida de los trabajadores, según la temporalidad incierta de la novela, se asemejan a las que caracterizaban la situación del obrero en la época de la gran industria, de acuerdo con lo expuesto en textos clásicos del pensamiento marxiano como La situación de la clase obrera en Inglaterra o el capítulo «La jornada laboral» del primero tomo de El capital. La yuxtaposición heterocrónica que Chejfec dispone en esta novela —recurso extensible a otras como El aire, Cinco o El llamado de la especie- se manifiesta en al menos dos episodios más: el de la destrucción de la maquinaria por parte de los obreros de la fábrica, acto que remeda la revuelta ludita del siglo XIX, y la parábola de G, el joven obrero que había logrado tal grado de calificación en el manejo de la maquinaria que, cuando esta es reemplazada por una tecnología nueva, decide negarse a trabajar y es, finalmente, desplazado.

Según la fórmula precisa de Josefina Ludmer, Boca de lobo parece revelar el «futuro del pasado obrero perdido» (105). Hay una mezcla deliberada de pasado y presente que configura una hipótesis sobre el futuro del trabajo. Una de las marcas del presente reside en lo que Zygmunt Bauman denomina la extraterritorialidad del poder (16), porque en la fábrica de Boca de lobo el poder irradia del establecimiento industrial pero, paradójicamente, no parece localizable. Esta circunstancia, entre otros efectos, produce un debilitamiento del impulso emancipatorio: ${ }^{4}$ Si ha pasado la época de las revoluciones sistémicas, es porque no existen edificios para alojar las oficinas del sistema, que podrían ser invadidas y capturadas por los revolucionarios» (Bauman:11). No se sabe de dónde provienen las decisiones como la de despedir a G, quien una mañana simplemente no apareció más junto a su vieja máquina, lo que indica que el mando se ejerce de manera impersonal. Es el carácter descentrado del capitalismo global que, según Mark Fisher (102-103), está prefigurado en el Castillo de la novela de Kafka y que, según Bauman, cobra la propiedad de un retorno al esquema antiguo de los «amos ausentes» (18).

Si la modernidad se caracterizó por la construcción de edificios destinados a durar, con una arquitectura maciza e indestructible que emulaba, en su ambición, a los monumentos de la Antiguiedad, ${ }^{5}$ ese deseo de perennidad ha caducado o, al menos, ha dejado de constituir un valor a ser perseguido en un tiempo presente que asume las formas inestables de la transitoriedad y la liviandad. La fábrica de Boca de lobo es, efectivamente, un monumento precario que se encuentra amenazado, a cada momento, por la disolución. En contrapartida, la fábrica de La mendiga parece hacerse eco de aquel sistema de lo perdurable, desde el momento en que el edificio es comparado con una pirámide de Egipto. Ahora bien, la analogía funciona solamente a condición de que se entienda la operación de Aira, que toma las ruinas industriales del presente y construye a partir de esa información inmediata un vasto mecanismo de ensoñación que convierte lo arruinado 
en maravilla. La fábrica en cuestión es un establecimiento industrial, ubicado en el corazón del Bajo Flores, que ha dejado de funcionar como tal y que es adquirido por un especulador inmobiliario. La madre de Rosa Nieves oficiará de cuidadora de esa suerte de palacio desmantelado al que la novela define como una ciudad personal, grande y enigmática. El destino de esta ruina industrial será sintomático, en la medida en que pondrá de relieve el enlace entre procesos de desregulación laboral, reconversión de zonas urbanas ociosas y negocios inmobiliarios: la fábrica abandonada será adquirida tiempo más tarde por un artista internacional para convertirla en su taller, según el fenómeno estudiado por Sharon Zukin en su libro de 1982, Loft living. ${ }^{6}$ Pero antes de que eso ocurra, la fábrica es el lugar desde donde Rosa observa panorámicamente el barrio, la complicada simplicidad de la villa miseria, su laberinto de calles y, por encima, el humo de las fábricas que todavía, en ese momento, funcionaban. La escena tiene para Rosa la atmósfera de fin de época: «si se avecinaba la noche en el barrio, cpor qué no se iba a avecinar también en un estilo de vida, en un modo de pensar, de representar, de sentir?» (85).

La vida de Rosa Nieves alternará, entonces, entre la casa de cuento de hadas de la abuela y el laberinto desmesurado de la madre. En una novela en la que cada personaje se define por su trabajo o por su falta de trabajo - en el pasado legendario del período peronista, evocado por la abuela de la protagonista, «había empleos públicos para todo el mundo» (54), pero esa época ha terminado—, ya se trate de artistas callejeros, ingenieros o agentes inmobiliarios, el único personaje que tiene trabajo como operario industrial es Orlandito Piñeyro, quien, acaso para contravenir el mandato paterno, consigue empleo en una industria que sí funciona: «la fábrica Suchard, que por ese entonces estaba en el barrio, en la Avenida Carabobo, justo donde ahora pasa la autopista» (75). Orlandito cumple con la trayectoria obrera de sindicalización y adopción de una ideología proletaria. Así, se convierte en la excepción, ya que es el solitario representante de un mundo del trabajo ligado a la época del fordismo, en un medio circundante que se revela modificado. En ese contexto de pérdida del empleo, todo trabajador deviene artista. Los ingenieros, ya jubilados, producen cine de vanguardia en su tiempo libre; los residentes del Hospital Piñeyro forman un grupo filodramático experimental bajo la dirección de Emeterio Cerro; el «famoso» escultor argentino compra el viejo establecimiento industrial para convertirlo en su taller, y su figura parece vincularse con la imagen actual del artista internacional que realiza obras majestuosas que compiten en las grandes bienales de arte; Rosa Nieves deviene xilofonista; y, mucho antes, la Revolución Libertadora barre con el trabajo de las clases populares pero, en su lugar, proporciona las condiciones para que se inicie «la era de la Libertad», en la que cada individuo queda librado a su propia iniciativa: «Ya divorciado del pueblo, el arte se hacía vanguardista, hermético, neurótico...» (55). Orlandito es el único que hace el camino inverso: abandona la confección de títeres y se incorpora al trabajo industrial.

Al igual que Chejfec, Aira también trabaja sobre la base de la estratificación temporal, pero a diferencia de aquel, no yuxtapone los tiempos sino que los mantiene separados. La infancia peronista de Rosa Nieves cede su lugar a la adolescencia durante los tiempos de la Libertadora y recala, finalmente, en el presente. Si antes el Bajo de Flores «lindaba con extensiones pampeanas» (Aira, 1998:56) y había zonas que solo podían atravesarse a caballo, de manera que los bordes de la ciudad coincidían aún con la llanura, en el presente del relato aquel pasado bucólico sobrevive únicamente en los murales colosales que representan «caballos salvajes pastando en las estepas pintados en colores fluorescentes» (16). Si bien el grueso del texto está compuesto 
por una analepsis que relata la vida de Rosa Nieves y de la comunidad del Bajo Flores, ese pasado está enmarcado por el presente del relato, que constituye, a su vez, una vasta écfrasis. Porque la novela es, en definitiva, la puesta en palabras de una serie televisiva sobre los médicos del Hospital Piñeyro de Flores protagonizada por Cecilia Roth. Quiere decir que la novela se presenta como una tira televisiva y, en consecuencia, apela a los lugares comunes del melodrama, los giros imprevistos y la espectacularidad risible propios del género. La novela (de Aira) es, en este sentido, una novela (de televisión) mala. Uno de los protagonistas de la serie se dispone a narrar las peripecias de Rosa Nieves a partir de su matrimonio con Rolf «Evito» Thiele, pero confunde las palabras: en lugar de Berlín pronuncia Brelín, de manera que inventa un suburbio bonaerense allí donde la trama había previsto una capital europea. La distracción tiene efectos decisivos en el desarrollo de la acción: «en televisión no se podía volver atrás, así que ahora habría que cambiar sobre la marcha todo el argumento... (...). A partir de ese momento entraban en la improvisación absoluta; había que inventarlo todo» (87-88). El malentendido refiere a la propia estética de lo malogrado que es una de las marcas de la escritura de Aira.

Cifrado en la trama de la novela, Aira vuelve a afirmar aquella poética que está disponible principalmente en los ensayos «Ars narrativa», «La innovación» $\mathrm{y}$ «La nueva escritura»:

Cuando había creído que ya no era nada ni nadie, volvía a hacer arte; habría podido jurar que la música ya estaba toda hecha, y de pronto, del fondo del adefesio, volvía el pop... (...). Iba hacia lo nuevo, hacia lo desconocido. La improvisación avanza siempre hacia el absoluto de lo nuevo; la suya transmitía su mensaje mediante la novedad. Un solo átomo viejo, una gota ya vista en el océano de las aguas nuevas, y su música no habría significado nada. (Aira, 2015:38)

La superproducción airiana es un fenómeno que se explica, por un lado, desde una lógica editorial, como el resultado de un impulso lamborghiniano —el dictum lamborghiniano materializado por otro- de publicación de libros que instala la pregunta por el vínculo entre vanguardia y mercado.? Pero también se explica por una decisión anterior que posibilita la proliferación de ediciones y que es, antes que todo, la invención de un procedimiento. Aira insiste en el concepto de «huida hacia adelante» para explicar el mecanismo básico de sus relatos. En otras palabras, lo que el concepto nombra es una ética de la escritura que se opone a la corrección, ${ }^{8}$ actividad que se había convertido en garantía de la calidad del producto final al que podía arribar un escritor. La cantidad de tiempo invertido por el artista en limar, pulir, perfeccionar el resultado primero de su escritura — es decir, el primer borrador — tenía una relación directamente proporcional con la composición de un buen texto. En efecto, los decálogos de la buena escritura redactados por autores como Hemingway, Quiroga o Faulkner enfatizaban que la tarea del escritor consistía, esencialmente, en corregir. Más cercano en el tiempo, Ricardo Piglia se erige como el principal representante de esa práctica de la literatura:

Escribir es sobre todo corregir, no creo que se pueda separar una cosa de otra. (...) Cierta disciplina de trabajo ha sido fundamental en mi formación como escritor. Joyce insistía, de un modo un poco maniático, en que había empleado 20.000 horas para escribir Ulises. Sería ridículo pensar que 20.000 horas de trabajo aseguran la escritura de un libro como Ulises, pero a la vez hay que decir que ese tiempo está en la textura del libro y eso es (también) lo que leemos al leer esa novela. (93-94) 
Contra esa cristalización del trabajo de la escritura, Aira inventa su propio concepto de «mala literatura», que le sirve además para resolver un problema, es decir, el callejón sin salida al que se enfrentó la novela modernista en su afán de superar («avanzar un paso o dos más», dice Aira) la novela decimonónica: «mientras Balzac escribió cincuenta novelas, y le sobró tiempo para vivir, Flaubert escribió cinco, desangrándose, Joyce escribió dos, Proust una sola. Y fue un trabajo que invadió la vida, la absorbió, como un hiperprofesionalismo inhumano» (Aira, 2000:165). De esta manera, Aira se posiciona en contra del trabajo de escritura como sufrimiento indecible que provoca un dolor absoluto y atroz, y en contra de la imagen de escritor en tanto sacerdote que renuncia a la vida para consagrarse a la escritura. ${ }^{9}$ La economía de esta práctica de la literatura supone, como lo señala la cita de Piglia, la entrega a una gran cantidad de tiempo de trabajo para obtener un rendimiento muy reducido. Aira, en cambio, enfatiza el valor de la improvisación, la no corrección, el error, configurando así una estética de lo malogrado que se presenta al modo de un método vanguardista que permita hacer avanzar un paso o dos más a la novela y que se asienta en una poética de la invención. La mala escritura es en Aira, como ha señalado Jens Andermann, «un proceso de liberación, un camino más allá de la represión» (193). Aún más, es una escritura que se presenta en oposición a la idea de trabajo: no hay laboriosidad alguna, no hay la destilación de un oficio; el acto escritural no produce como resultado una artesanía trabajada por la pericia del artesano; la superproducción parece brotar, en cambio, por efecto espontáneo, sin estar sujeta al desgaste ni al cansancio. Y que esa conceptualización acerca de la mala literatura que tiene su génesis en torno a esos años (no más temprano que 1987, no más tarde que 1991) tiene efectos directos sobre la textualidad airiana: descuido estilístico, personajes compuestos con trazos gruesos, incoherencias argumentales, finales precipitados y disparatados; en definitiva, elementos que parecen precipitar las novelas de Aira «hacia la mala escritura y el papelón» (Andermann:188).

Por otro lado, en Boca de lobo, el narrador que ha leído muchas novelas pasa a escribir la propia, que es, presumiblemente, la que estamos leyendo. El tiempo de la escritura sucede al tiempo de la vida, de manera que el trabajo literario asume una tonalidad crepuscular: ${ }^{10}$ es aquella actividad que se desarrolla cuando un cúmulo de experiencias ha llegado a su fin y se activa el tiempo de la reminiscencia. Sin embargo, como dice Laera, «la creación (...) nunca resulta del todo compensatoria», porque finalmente «se trata siempre de una compensación tan frágil como transitoria» (207). Así, la escritura es melancólica y vacilante, ya que al tiempo que se adhiere a la pérdida —el tiempo perdido de la vida— fracasa en su voluntad de restaurar lo acontecido y no hace más que exhibir la imposibilidad de la tarea afrontada. Con todo, la imposibilidad no clausura sino que estimula la práctica de la escritura. La ficcionalización del trabajo de creación en Boca de lobo no solamente plantea una teoría de la producción literaria, sino que reenvía a la estética de Chejfec en su conjunto, en el sentido de que esa ficcionalización alude a los problemas con los que el propio autor se ha enfrentado a lo largo de su trayectoria. En un proyecto de autobiografía escrito en tercera persona para Claudia del Río, Chejfec explicita la desconfianza que siempre le generó la escritura ficcional entendida exclusivamente como la facultad de escribir historias: «Debido a ello se ha inclinado por tramar límites entre la construcción de la realidad y su desorganización, como una forma de apelar a la ambigüedad de los significados, que en general se presentan claros y confusos al mismo tiempo» (2017:15). Boca de lobo se instala en ese espacio liminar entre realidad y ficción para postular una estética que explore la inestabilidad de 
los sentidos. Esa tentativa se lleva a cabo formalmente apelando a la circularidad, la repetición y el ejercicio hipotético-conjetural que se inscribe, como lo señaló tempranamente Sarlo, en la sintaxis de la frase chejfequiana.

Por lo tanto, si la narración en Aira brota de la fantasía de un texto que se escribe solo, a mano alzada," en Chejfec es el resultado, en cambio, de un trabajo reposado por medio del cual la reminiscencia se traduce laboriosamente a la letra escrita. ${ }^{12}$ Las dos novelas exploran el mundo del trabajo en el momento mismo en que sus formas han perdido los atributos que tuvieron durante buena parte del siglo XX y en que se encuentran en vías de transformación hacia otros avatares de lo laboral que todavía no se adivinan con certeza. La exhibición de los procesos de construcción del relato, que reenvía a la poética de cada autor, expresa los diferentes modos en que aquel mundo social se convierte en objeto de la narración. Porque la novela de Chejfec construye un dispositivo hipotético que procura asediar lo real — la precariedad de la vida proletaria — basado en la inestabilidad de la conjetura, y este ejercicio mismo es el que atraviesa, en tanto problema, la relación del narrador-protagonista con la escritura. En el caso de Aira, La mendiga se presenta como una novela «mala» que asume la serialidad de las tiras televisivas, hechas en base a estereotipos, golpes de efecto e improvisación. El texto toma elementos de la realidad inmediata y de la historia social para hacer con ellos un cuento de hadas exótico, precipitado, que mira el fin de una época con el prisma de la ensoñación.

\section{Notas}

1 Como acostumbra a hacerlo con sus textos de ficción, Aira fecha La mendiga el 27 de diciembre de 1994, cuatro años antes de su edición. Por su parte, Chejfec publica un adelanto de Boca de lobo con el título «Pater, fragmento de una novela en preparación» en revista Punto de vista $n^{\circ} 57$ (abril de 1997).

$2 \mathrm{El}$ proceso de gestación de suburbios industriales se consolida en las ciudades de Latinoamérica principalmente a partir de la década de 1930. Así lo describe José Luis Romero: «En algunas ciudades — Buenos Aires, por ejemplo— los suburbios industriales constituyen un "cordón" que las rodea (...). La formación de una zona industrial, como la de Avellaneda, Alsina o San Justo en Buenos Aires, como la que se ordena alrededor de la avenida Vicuña Mackena en Santiago, como la que concentra la producción de harina de pescado en Lima o como la que se ha constituido en Medellín o Monterrey, supone no sólo la instalación de las plantas sino, inmediatamente, el surgimiento de barrios habitacionales y la red de negocios adecuados al medio» (279).

3 Son vacilantes porque el vínculo de Delia con el lenguaje es definido en diferentes ocasiones como un vínculo, por lo menos, peculiar: «No hace falta repetir que Delia se expresaba con largos silencios, y cuando hablaba sus palabras siempre

resultaban escasas» (88). Quiere decir que buena parte de lo que leemos puede bien ser consecuencia de un malentendido o, también, de un sobreentendido.

4 Es sintomático que cuando Beatriz Sarlo subraya el componente utópico que se expresa en la solidaridad de la comunidad proletaria de la novela, lo haga enfatizando el costado ético y no el político: «esos hombres y mujeres están como alejados de su propio yo, enajenados de toda voluntad que no sea cumplir con su trabajo. Sin embargo, alcanzan a realizar actos mínimos que atestiguarían precisamente la persistencia de un yo y de una dimensión ética» (399). Nuevamente, el único acto de rebelión con tintes emancipatorios, que, aunque ineficaz, podría fundar una respuesta política a la situación obrera, es el protagonizado por G.

5 Bauman destaca la grandiosidad de las construcciones de la sociedad industrial: «El predio en construcción del nuevo orden industrial estaba salpicado aquí y allá de monumentos dedicados a ese poder y a esa ambición, monumentos que finalmente resultaron o no indestructibles pero que ciertamente fueron construidos para parecerlo: por ejemplo, las gigantescas fábricas atiborradas de enormes máquinas y multitudes de operarios, o las densas redes de canales, puentes y líneas 
férreas, jalonadas por las majestuosas estaciones de tren que emulaban antiguos templos erigidos para la adoración de lo eterno y para eterna gloria de los fieles» (153).

6 Zukin (1982) analiza el proceso de revalorización de establecimientos industriales y lofts en desuso en la ciudad de Nueva York, proceso que se inició en los años 1960 y que tuvo a los artistas como agentes esenciales de la transformación urbana de fin de siglo. Martha Rosler comenta el estudio de Zukin en los siguientes términos: «En este notable libro, Zukin expone una teoría del cambio urbano según la cual los artistas y todo el sector de las artes visuales — especialmente las galerías comerciales, los espacios regenteados por artistas y los museos- son un motor principal para la reconversión de la ciudad posindustrial y para la renegociación de los inmuebles en beneficio de las élites» (90).

7 La autora que trabaja este problema es Sandra Contreras, quien explora el vínculo a la vez problemático y fundante entre la obra de Aira y la industria cultural. Contreras señala que se trata de una relación desviada e irónica con el mercado, pues si, por un lado, el trabajo literario se transmuta en superproducción, por el otro, el efecto inmediato de esa transmutación es la devaluación de la obra «por su exposición reiterada a la banalidad, al disparate, al error» (Contreras:75).

8 Graciela Montaldo subraya el término «adefesio» —que aparece en la cita más arriba— para definir los alcances de la estética airiana: «Adefesios y monstruos pueblan una literatura que ha dado el paso al vacío: ha borrado la categoría de corrección, la de escritura, la de lo bello, la de la utilidad, la de la ética, la del realismo» (100).

9 Seguimos, en este caso, el análisis de Roland Barthes sobre el trabajo del estilo en Flaubert como tormento que exige un irrevocable adiós a la vida. Contra Barthes, Jacques Rancière elige recuperar otra imagen para expresar la relación de Flaubert con la escritura: «Más astutos que los desmitificadores del siglo XX, los críticos contemporáneos de Flaubert señalan lo que liga el culto de la frase a la valorización del trabajo dicho sin frase alguna: el esteta flaubertiano es un picapedrero» (71).

10 Hay otros indicios que colocan a la escritura del lado de lo crepuscular: el narrador gesta la novela a condición de abandonar la vida procreada; los calcos de los obreros son pura adherencia a la vida de donde emanaron, mientras que las novelas serían letra muerta; el narrador se identifica con el vecino que agoniza en el departamento que está frente al suyo.

11 Esto genera, en palabras de Marina Ríos, una «ilusión de concomitancia entre el presente enunciativo y el narrativo» (47).

$12 \mathrm{Si}$ el sistema de deudas del arte narrativo airiano incluye principalmente a Lamborghini y Copi, el de Chejfec sin lugar a dudas tiene como referencia central a Saer. Para esto último, véase Siskind (35-36).

\section{Referencias}

Aira, C. (1998). La mendiga. Buenos Aires: Literatura Random House, 2015.

Aira, C. (2000). La nueva escritura. Boletín del Centro de Estudios de Teoría y Crítica Literaria, (8), 165-170.

Andermann, J. (2015). La operación Aira: literatura argentina y procedimiento. En Kailuweit, R.; Jaeckel, V. y Di Tullio, A. (Eds.). Roberto Arlty el lenguaje literario argentino. Madrid/Frankfurt am Main: Iberoamericana/Vervuert, 183-197.

Barthes, R. (2000). Flaubert y la frase. El grado cero de la escritura. Nuevos ensayos críticos. México: Siglo XXI, 191-204.Traducción de Rosa, N.

Bauman, Z. (2000). Modernidad líquida. Buenos Aires: Fondo de Cultura Económica. Traducción de Rosenberg, M. en colaboración con Arrambide Squirru, J.

Chejfec, S. (1997). Pater, fragmento de una novela en preparación. Punto de vista, (57), 24-27.

Chejfec, S. (2000). Boca de lobo. Buenos Aires: Alfaguara, 2009.

Chejfec, S. (2017). Teoría del ascensor. Buenos Aires: Entropía.

Contreras, S. (2007). Superproducción y devaluación en la literatura argentina reciente. En CárcamoHuechante, L.E.; Fernández Bravo, A. y Laera, A. (Comps.). El valor de la cultura. Arte, literatura y mercado en América LatinaRosario: Beatriz Viterbo, 67-86. 
Fisher, M. (2016). Realismo capitalista. ¿No hay alternativa? Buenos Aires: Caja Negra. Traducción de Iglesias, C.

Laera, A. (2012). Los trabajos: creación y escritura en Boca de lobo y otras novelas de Chejfec. En Niebylski,

D.C. (Ed.). Sergio Chejfec: Trayectorias de una escritura. Pittsburgh: Instituto Internacional de Literatura Iberoamericana, 201-218.

Laera, A. (2016). Más allá del dinero: ficciones del trabajo en la Argentina contemporánea y la fetichización del escritor. Badebec, 6(11), 158-173.

Ludmer, J. (2002). Temporalidades del presente. Boletín del Centro de Estudios de Teoría y Crítica Literaria, (10), 91-112.

Montaldo, G. (2010). Aira: un arte basado en la incorreción. El cuestionamiento de las instituciones en una vanguardia finisecular. En Carbone, R. y Ojeda, A. (Comps.). De Alfonsín al menemato (1983-2001). Buenos Aires: Paradiso, 94-106.

Piglia, R. (1993). El laboratorio de la escritura. Crítica y ficción. Buenos Aires: Siglo Veinte, 89-97.

Rancière, J. (2014). El reparto de lo sensible. Buenos Aires: Prometeo Libros. Traducción de Padró, M.

Ríos, M. (2014). Dispositivo de lectura en La villa de César Aira y Los fantasmas del masajista de Mario Bellatin: cuerpos, escritura y performance. Badebec, 4(7), 42-60.

Romero, J.L. (2009). La ciudad occidental. Culturas urbanas en Europa y América. Buenos Aires: Siglo XXI.

Rosler, M. (2017). Clase cultural. Arte y gentrificación. Buenos Aires: Caja Negra. Traducción de Jorge, G.

Sarlo, B. (2007). El amargo corazón del mundo. Escritos sobre literatura argentina. Buenos Aires: Siglo XXI, 398-400.

Siskind, M. (2005). Entrevista a Sergio Chejfec. Hispamérica, (100), 35-46.

Zukin, S. (1982). Loft Living. Culture and Capital in Urban Change. Baltimore/London: The John Hopkins University Press. 